\title{
Multicenter Trial of Sentinel Node Biopsy for Breast Cancer Using Both Technetium Sulfur Colloid and Isosulfan Blue Dye
}

\author{
Lorraine Tafra, MD, ${ }^{*}$ Donald R. Lannin, MD, † Melvin S. Swanson, PhD, † Jason J. Van Eyk, BS, † Kathryn M. Verbanac, PhD, † \\ Arlene N. Chua, MD, † Peter C. Ng, MD, † Maxine S. Edwards, RN, † Bradford E. Halliday, MD, † C. Alan Henry, MD, \\ Linda M. Sommers, MD, $\S$ Claire M. Carman, MD,\| Melinda R. Molin, MD, ๆ John E. Yurko, MD, ${ }^{* *}$ Roger R. Perry, MD, ††

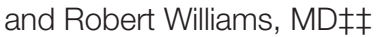

From The *Breast Center, Anne Arundel Medical Center, Annapolis, Maryland, and the †Department of Surgery, Leo Jenkins Cancer Center, East Carolina University, Greenville, North Carolina; $\neq$ Breast Care Center of the Blue Ridge, Roanoke, Virginia (Henry); \$ IMartha Jefferson Hospital, Charlottesville, Virginia (Sommers); | Breast Care Specialists, PC, Norfolk, Virginia (Carman); IMercy Hospital, Portland, Maine (Molin); ${ }^{* *}$ Carteret General Hospital, Morehead City, North Carolina (Yurko); t+Eastern Virginia Medical School, Norfolk, Virginia (Perry); and +†Lewis-Gale Medical Center, Salem, Virginia (Williams)

\section{Objective}

To determine the factors associated with false-negative results on sentinel node biopsy and sentinel node localization (identification rate) in patients with breast cancer enrolled in a multicenter trial using a combination technique of isosulfan blue with technetium sulfur colloid (Tc99).

\section{Summary Background Data}

Sentinel node biopsy is a diagnostic test used to detect breast cancer metastases. To test the reliability of this method, a complete lymph node dissection must be performed to determine the false-negative rate. Single-institution series have reported excellent results, although one multicenter trial reported a false-negative rate as high as 29\% using radioisotope alone. A multicenter trial was initiated to test combined use of Tc99 and isosulfan blue.

\section{Methods}

Investigators (both private-practice and academic surgeons) were recruited after attending a course on the technique of sentinel node biopsy. No investigator participated in a learning trial before entering patients. Tc99 and isosulfan blue were injected into the peritumoral region.

\section{Results}

Five hundred twenty-nine patients underwent 535 sentinel node biopsy procedures for an overall identification rate in finding a sentinel node of $87 \%$ and a false-negative rate of $13 \%$. The identification rate increased and the false-negative rate decreased to $90 \%$ and $4.3 \%$, respectively, after investigators had performed more than 30 cases. Univariate analysis of tumor showed the poorest success rate with older patients and inexperienced surgeons. Multivariate analysis identified both age and experience as independent predictors of failure. However, with older patients, inexperienced surgeons, and patients with five or more metastatic axillary nodes, the falsenegative rate was consistently greater.

\section{Conclusions}

This multicenter trial, from both private practice and academic institutions, is an excellent indicator of the general utility of sentinel node biopsy. It establishes the factors that play an important role (patient age, surgical experience, tumor location) and those that are irrelevant (prior surgery, tumor size, Tc99 timing). This widens the applicability of the technique and identifies factors that require further investigation.
Since the description of sentinel lymph node biopsy (SNB) in the early 1990s, results for breast cancer have been

Supported by the Department of Defense Grant \#DAMA17-98-1-8097, East Carolina University School of Medicine Faculty Research Grants \#265507 and \#265512, and American Cancer Society Institutional Research Grant \#5-89811.

Correspondence: Lorraine Tafra, MD, Director, The Breast Center, Anne reported in several single-institution series. ${ }^{1-4}$ These results were promising, and the sentinel node predicted the presence or absence of disease in the remaining axillary lymph

Arundel Medical Center, 2001 Medical Parkway, Annapolis, MD 21401.

E-mail: 1tafra@AAHS.org

Accepted for publication April 15, 2000. 
nodes in most patients. Techniques varied in these trials, using isosulfan blue (IB) alone, technetium sulfur colloid (Tc99) alone, or both combined. The only multicenter trial validating this new surgical technique used Tc99 alone. ${ }^{5}$ Other series involving large number of patients using IB and Tc99 combined have been criticized for either failing to report an accurate false-negative rate $^{6}$ or not permitting calculation of this rate by enrolling patients who did not undergo complete lymph node assessment. ${ }^{4}$

The impetus to perform SNB alone is great, because there are no data to support the contention that patients without axillary metastases will benefit from the potentially morbid procedure of axillary dissection. Unfortunately, as SNB moves to replacing axillary node dissection, the opportunity to obtain accurate data on the false-negative rate under various conditions is lost. The studies to date have tightly restricted the conditions under which lymphatic mapping is performed (i.e., size of tumor, timing of Tc99, and prior breast surgery). There is little information, however, to support the premise that these factors actually affect the diagnostic accuracy of the technique.

Before moving to performing SNB alone as the standard of care for patients with breast cancer, it will be important to determine which patients can benefit as well as which may be ill served by the technique. Patients must undergo complete axillary node dissection to determine the falsenegative rate under various conditions to determine which patients are appropriate candidates for SNB. The purpose of this trial was to determine the factors that influence lymphatic mapping in a multicenter trial by performing SNB followed by complete lymph node dissection.

\section{METHODS}

A multicenter trial was conducted from February 1997 through May 1999 and enrolled patients from surgical investigators who participated in a formal lymphatic mapping and SNB course. The course included hands-on experience in a porcine model that has previously been described. ${ }^{7}$ The principal investigator visited most investigative sites at least once. Institutional review board approval was obtained from all investigative sites, and all patients gave informed consent. Investigative sites included both private-practice settings and academic centers.

The technique of SNB included a peritumoral injection with 2 to $5 \mathrm{~mL}$ IB (American Regent Laboratories, Inc., Shirley, $\mathrm{NY}$ ) and a peritumoral injection of $1 \mathrm{mCi}(37 \mathrm{MBq}) \mathrm{Tc} 99$ (CIS-US, Bedford, MA). The Tc99, in a volume of $4 \mathrm{~mL}$, was injected at 12, 3, 6, and 9 o'clock positions around the tumor, biopsy site, or lumpectomy cavity. Each investigative site had a choice of using filtered or unfiltered Tc99. Filtered Tc99 was obtained by passing radiocolloid over a $0.2-\mu \mathrm{m}$ filter. Only the timing of IB injection was restricted, and it was injected immediately before surgery. Intraoperative use of the gamma probe was required on all patients to aid in the identification of the sentinel node. A sentinel node was defined as any node that was blue, both blue and hot (with hot defined as an ex vivo count of 10 times the background count or more), or hot only node, and the location of all sentinel nodes in vivo was recorded. The background count was taken from the lower extremity or abdomen. Gamma probe counts were obtained on the axillary dissection specimen, all surrounding nodal basins, the primary injection site, and the sentinel nodes in vivo and ex vivo. In most cases the sentinel node was harvested before performing the definitive surgery on the breast. A standard level 1 and 2 lymph node dissection was performed after sentinel node excision.

Exclusion criteria for patients were clinically suspicious or positive axillary nodes, pregnancy, and extensive cardiac, pulmonary, or renal disease. Data collected during surgery included the type of gamma probe used (C-track [Carewise, Morgan Hill, CA], Neoprobe [Neoprobe Corp., Dublin, OH], and Navigator [U.S. Surgical, Bedford, $\mathrm{OH}$ ]), technique of diagnosis (including patients undergoing prior lumpectomy, open biopsy, fine-needle aspiration biopsy, or core biopsy), tumor size, time of Tc99 injection, time of sentinel node harvest, and use of filtered versus unfiltered Tc99.

A radiation safety officer participated in the start-up of the protocol at each site. Radiation exposure was monitored in the radiology suite, the operating room, and the pathology laboratory. The primary tumor or site of Tc99 injection was kept for 24 to 48 hours before pathologic analysis to allow sufficient decay.

All sentinel nodes were serially sectioned, and every other section was submitted for additional laboratory studies. Each section sent to pathology was analyzed using multiple sections. The majority of hematoxylin-and-eosinnegative nodes were analyzed by immunohistochemistry with a cytokeratin cocktail (Cytokeratin AE1:3; Boehringer Mannheim Corp., Indianapolis, IN).

The Fisher exact test for nominal variables was used to compare success rates and false-negative rates according to surgeon experience, patient age, tumor size, location of the primary tumor, histologic tumor type, type of previous biopsy, filtered or unfiltered Tc99, time from injection to surgery, number of positive nodes, number of sentinel nodes found, type of gamma probe used, and ex vivo sentinel node counts. Any variables that had a probability value of less than 0.25 were used to develop a multivariate logistic regression model to predict failure to find a sentinel node. The Hosmer-Lemeshow goodness-of-fit criterion was used to determine the adequacy of the model. The identification rate in this trial is defined as the ability to identify a sentinel node successfully on a per-procedure basis (a few patients underwent bilateral SNB). The false-negative rate was defined as the number of procedures with a negative sentinel node (and a positive nonsentinel node) divided by the procedures with positive axillary lymph nodes. A one-way analysis of variance was used to compare the mean number of nodes found and mean ex vivo counts between injection intervals, type of previous biopsy, and filtered or unfiltered 
Tc99. The Fisher exact test was used to assess the relation between the number of sentinel nodes found and the number of those nodes that were positive. SPSS 8.0 statistical software (SPSS, Inc., Chicago, IL) was used for the statistical analysis. All reported probability values for the Fisher exact test were two-tailed.

\section{RESULTS}

A total of 529 patients were enrolled in the study. The mean number of lymph nodes obtained during axillary dissection was $13 \pm 6$. Forty-eight surgeons participated in the trial and contributed a median of 18 patients each. Characteristics of the study population are summarized in Table 1. Most of the patients had upper outer quadrant lesions and pathology consistent with infiltrating ductal carcinoma and underwent lumpectomy (341 [70\%]) versus mastectomy (146 [30\%]). The mean age of the entire group was 57 years (range 26-89). Six patients underwent bilateral SNB for bilateral breast cancer. Sixteen percent of patients were found to have an internal mammary basin count greater than background but SNB was not performed, although the option was available to the investigators. Table 2 presents the status of the lymph nodes in all SNB procedures where a sentinel node was found. Of the 535 SNB procedures, a sentinel node was identified in 466 , for an identification rate of $87 \%$. The false-negative rate for the group was $13 \%$. The accuracy of the sentinel nodes to detect metastatic disease was $96 \%$, and the negative predictive value was $95 \%$. Forty-six patients were excluded from the false-negative analysis for lack of a complete lymph node dissection, but they were included in analysis of success (or identification) rates.

A univariate analysis that examined eight variables (Table 3 ) found that only patient age (50 years or older) and surgeon experience (performance of fewer than 10 cases) significantly affected the identification rate of finding the sentinel node. Identification rates were lower in patients who had a prior lumpectomy, five or more positive lymph nodes on axillary dissection, lesions in the medial quadrant, or Tc99 timing intervals less than 30 minutes, but these did not reach statistical significance. A multivariate analysis showed that surgeon experience and age were independent predictors of failed SNB (Table 4).

The number of false-negative results was small $(\mathrm{n}=18)$. A univariate analysis examined nine variables to determine their influence on the false-negative rate (Table 5). Although the false-negative rate was high among inexperienced surgeons and procedures yielding only one sentinel node, only the location of a tumor in the inner quadrant reached statistical significance. Additional analysis indicated that the location effect could not be explained on the basis of variation in the average number of sentinel nodes found between locations.
Table 1. PATIENT CHARACTERISTICS

\begin{tabular}{|c|c|c|}
\hline Characteristic & Groups & \# Pts. $(\%)$ \\
\hline \multirow[t]{4}{*}{ Tumor type } & Infiltrating ductal & $393(74 \%)$ \\
\hline & Infiltrating lobular & $36(7 \%)$ \\
\hline & Other & $92(16 \%)$ \\
\hline & Unknown & $14(3 \%)$ \\
\hline \multirow[t]{7}{*}{ Tumor location } & Upper outer quadrant & $244(46 \%)$ \\
\hline & Upper inner quadrant & $66(12 \%)$ \\
\hline & Lower outer quadrant & 45 (8\%) \\
\hline & Lower inner quadrant & $39(7 \%)$ \\
\hline & Central & $56(11 \%)$ \\
\hline & Other & $70(13 \%)$ \\
\hline & Unknown & $15(3 \%)$ \\
\hline \multirow[t]{4}{*}{ Tumor size } & $<2 \mathrm{~cm}$ & $289(54 \%)$ \\
\hline & $2-5 \mathrm{~cm}$ & 192 (36\%) \\
\hline & $>5 \mathrm{~cm}$ & $16(3 \%)$ \\
\hline & Multifocal & 38 (7\%) \\
\hline \multirow[t]{4}{*}{$\begin{array}{l}\text { Prior surgical } \\
\text { procedure }\end{array}$} & $\begin{array}{l}\text { Tumor intact (fine-needle } \\
\text { aspiration or core) }\end{array}$ & $334(62 \%)$ \\
\hline & Open biopsy & 165 (31\%) \\
\hline & Lumpectomy & $34(6 \%)$ \\
\hline & Unknown & $2(<1)$ \\
\hline \multirow[t]{3}{*}{ Tc99 preparation } & Filtered & 211 (39\%) \\
\hline & Unfiltered & $321(60 \%)$ \\
\hline & Unknown & $3(1 \%)$ \\
\hline \multirow{4}{*}{$\begin{array}{l}\text { Gamma probe } \\
\text { used }\end{array}$} & C-trak & 257 (48\%) \\
\hline & Neoprobe & $204(38 \%)$ \\
\hline & Navigator & $66(12 \%)$ \\
\hline & Unknown & $8(2 \%)$ \\
\hline
\end{tabular}

Fourteen patients in the trial received preoperative chemotherapy. There were no false-negative results, and a sentinel node was identified in each patient. Lymphovascular invasion data were available in 284 patients. The success rate was $80 \%$ in the 50 patients with this tumor characteristic versus $87 \%$ in patients whose tumors lacked lymphovascular invasion $(P=\mathrm{NS})$.

Figure 1 shows the false-negative rates and identification rates for increasing patient age: the success rate steadily decreased and the false-negative rate varied widely over these age groups. With increasing surgeon experience, the falsenegative rate decreased and the identification rate increased (Fig. 2).

A total of 1,055 sentinel nodes were found (mean $2.2 \pm$ 1.4 per patient). Most patients had either one (41\%) or two

\section{Table 2. NUMBER OF PROCEDURES WITH METASTASES}

\begin{tabular}{lccc}
\hline & \multicolumn{2}{c}{ Axillary Nodes } & \\
\cline { 2 - 3 } Sentinel & Positive & Negative & Total \\
Nodes & 122 & - & 122 \\
Positive & 18 & 326 & 344 \\
Negative & 140 & 326 & 466 \\
Total & & & 4 \\
\hline
\end{tabular}




\begin{tabular}{|c|c|c|}
\hline \multicolumn{3}{|c|}{$\begin{array}{l}\text { Table 3. SENTINEL NODE } \\
\text { IDENTIFICATION RATE }\end{array}$} \\
\hline Variable & $\begin{array}{c}\text { Identification } \\
(\%)\end{array}$ & $\begin{array}{c}P \\
\text { Value }\end{array}$ \\
\hline \multicolumn{3}{|l|}{ Age (years) } \\
\hline$<50$ & 95.0 & \\
\hline$\geq 50$ & 84.6 & .001 \\
\hline \multicolumn{3}{|l|}{ Prior surgery } \\
\hline Fine-needle aspiration/core biopsy & 86.8 & \\
\hline Open biopsy & 90.6 & \\
\hline Lumpectomy & 81.8 & .17 \\
\hline \multicolumn{3}{|l|}{ Tc99 Status } \\
\hline Filtered & 87.3 & \\
\hline Unfiltered & 88.5 & .68 \\
\hline \multicolumn{3}{|l|}{ Total positive nodes } \\
\hline$<5$ & 88.0 & \\
\hline$\geq 5$ & 75.0 & .17 \\
\hline \multicolumn{3}{|l|}{ Injection time } \\
\hline$<30$ minutes & 80.8 & \\
\hline$\geq 30$ minutes & 88.8 & .06 \\
\hline \multicolumn{3}{|l|}{ Tumor size } \\
\hline$<2 \mathrm{~cm}$ & 86.4 & \\
\hline $2-5 \mathrm{~cm}$ & 89.0 & \\
\hline$>5 \mathrm{~cm}$ & 87.5 & .72 \\
\hline \multicolumn{3}{|l|}{ Tumor location } \\
\hline Inner & 83.3 & \\
\hline Outer & 89.4 & \\
\hline Central & 94.4 & .10 \\
\hline \multicolumn{3}{|l|}{ Surgeon experience } \\
\hline$<10$ cases & 82.1 & \\
\hline$\geq 10$ cases & 91.8 & .002 \\
\hline
\end{tabular}

(30\%) sentinel nodes found; $29 \%$ had three or more. There was an increased chance $(P=.025)$ of having a positive sentinel node if more than one sentinel node was found (Table 6). This translated into a lower false-negative rate (see Table 5). The number of sentinel nodes found had no bearing on the overall chance of having positive axillary nodes or on the number of positive nodes (data not shown).

Factors affecting the number of sentinel nodes obtained were examined, and the results are shown in Table 7. Older patients were found to have significantly fewer sentinel nodes. With increasing injection interval, the mean number of sentinel nodes obtained increased $(P=.01)$.

\section{Table 4. MULTIVARIATE ANALYSIS OF FACTORS AFFECTING DECREASED SUCCESS IN FINDING A SENTINEL NODE}

\begin{tabular}{lrrr}
\hline Variable & $\begin{array}{c}\text { Failure } \\
\text { Rate }\end{array}$ & $\begin{array}{c}\text { Odds } \\
\text { Ratio }\end{array}$ & $\begin{array}{c}\text { Odds Ratio } \\
\mathbf{( 9 5 \% ~ C l )}\end{array}$ \\
\hline $\begin{array}{l}\text { Age (years) } \\
\quad<50\end{array}$ & 5.1 & 1.00 & \\
$\quad \geq 50$ & 15.4 & 3.46 & $1.31-9.22$ \\
$\begin{array}{c}\text { Experience } \\
>10 \text { cases }\end{array}$ & 8.2 & 1.00 & \\
$\leq 10$ cases & 17.9 & 2.72 & $1.30-5.71$ \\
\hline
\end{tabular}

Table 5. FACTORS AFFECTING FALSE-NEGATIVE RATE

\begin{tabular}{|c|c|c|}
\hline Variable & $\begin{array}{c}\text { False- } \\
\text { Negative } \\
\text { Rate (\%) }\end{array}$ & $\begin{array}{c}P \\
\text { Value }\end{array}$ \\
\hline \multicolumn{3}{|l|}{ Age (years) } \\
\hline$<50$ & 10.3 & \\
\hline$\geq 50$ & 15.1 & .60 \\
\hline \multicolumn{3}{|l|}{ Prior surgery } \\
\hline Fine-needle aspiration/core biopsy & 14.3 & \\
\hline Open biopsy & 11.4 & \\
\hline Lumpectomy & 11.1 & .90 \\
\hline \multicolumn{3}{|l|}{ Tc99 status } \\
\hline Filtered & 10.9 & \\
\hline Unfiltered & 15.0 & .61 \\
\hline \multicolumn{3}{|l|}{ Total positive nodes } \\
\hline$<5$ & 12.2 & \\
\hline$\geq 5$ & 25.0 & .20 \\
\hline \multicolumn{3}{|l|}{ Injection time } \\
\hline$<30$ minutes & 17.2 & \\
\hline$\geq 30$ minutes & 12.2 & .54 \\
\hline \multicolumn{3}{|l|}{ Tumor size } \\
\hline$<2 \mathrm{~cm}$ & 17.3 & \\
\hline $2-5 \mathrm{~cm}$ & 11.9 & \\
\hline$>5 \mathrm{~cm}$ & 0.0 & .43 \\
\hline \multicolumn{3}{|l|}{ Tumor location } \\
\hline Inner & 30.0 & \\
\hline Outer & 6.9 & \\
\hline Central & 10.0 & .02 \\
\hline \multicolumn{3}{|l|}{ Surgeon experience } \\
\hline$<30$ cases & 15.5 & \\
\hline$\geq 30$ cases & 4.0 & .19 \\
\hline \multicolumn{3}{|l|}{ Number of sentinel nodes } \\
\hline 1 & 20.8 & \\
\hline$\geq 2$ & 9.2 & .07 \\
\hline
\end{tabular}

Characteristics of the sentinel nodes were available for 849 nodes. Sixty-four (7\%) of these were blue only (radiation activity less than 10 times background). Of the remaining sentinel nodes, 57\% were both hot and blue, and 36\% were hot only.

The relation between the number of sentinel nodes and the experience of the surgeon is presented in Table 8 and was not statistically significant. The data suggest that both inexperience and number of sentinel nodes found may each independently affect the false-negative rate. Using multivariate logistic regression, we found that the odds ratio for inexperience after adjusting for the number of sentinel nodes found was $5.2(P=.064$; likelihood ratio test $)$.

The pattern of uptake of Tc99 by the sentinel node differed depending on whether the Tc99 was filtered (Table 9). Because many patients had more than one sentinel node and counts varied on each, calculations were made on both the hottest node (mean hottest node counts) and all the sentinel nodes (mean counts, all sentinel nodes). In the unfiltered group, counts on the sentinel nodes increased steadily with increasing time after Tc99 injection. In the 


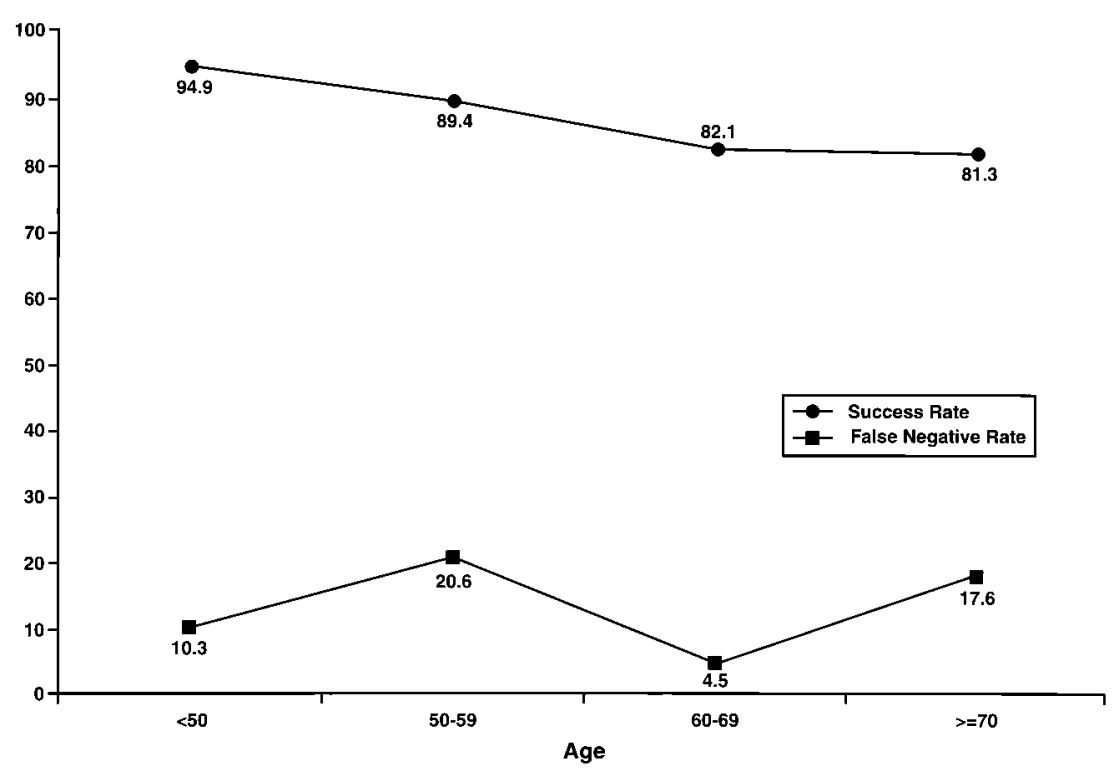

Figure 1. Adverse affects (decreased success rate of sentinel node biopsy) of increasing patient age.

filtered group, however, the counts increased rapidly between 21 and 60 minutes and then decreased.

The positive SN was the hottest node in $77 \%$ of the patients with a positive sentinel node in whom more than one sentinel node was found. In $23 \%$ of the cases, however, the positive node would have been missed if only the hottest node had been removed.

\section{DISCUSSION}

Since the publication of the first series on SNB for breast cancer, ${ }^{8}$ there has been overwhelming enthusiasm for development of this technique. SNB represents a major advance because it is not only minimally invasive but also, despite less surgery, improves the accuracy of pathologic staging. ${ }^{9}$ This study was performed to delineate the factors that are responsible for a false-negative sentinel node or failure to identify a sentinel node when a combined Tc99 and IB technique is used. The investigators were from a variety of centers and consisted of general surgeons as well as breast specialists, so it is an excellent indicator of the general utility of the technique. The results indicate that caution must be used when performing SNB in older patients and patients with medial quadrant lesions. In addition, it is clear from this data that the level of surgical expertise with the technique is crucial. Performance of at least 30 cases is required to ensure that the success rate exceeds $90 \%$ and the false-negative rate drops to less than $5 \%$. The data

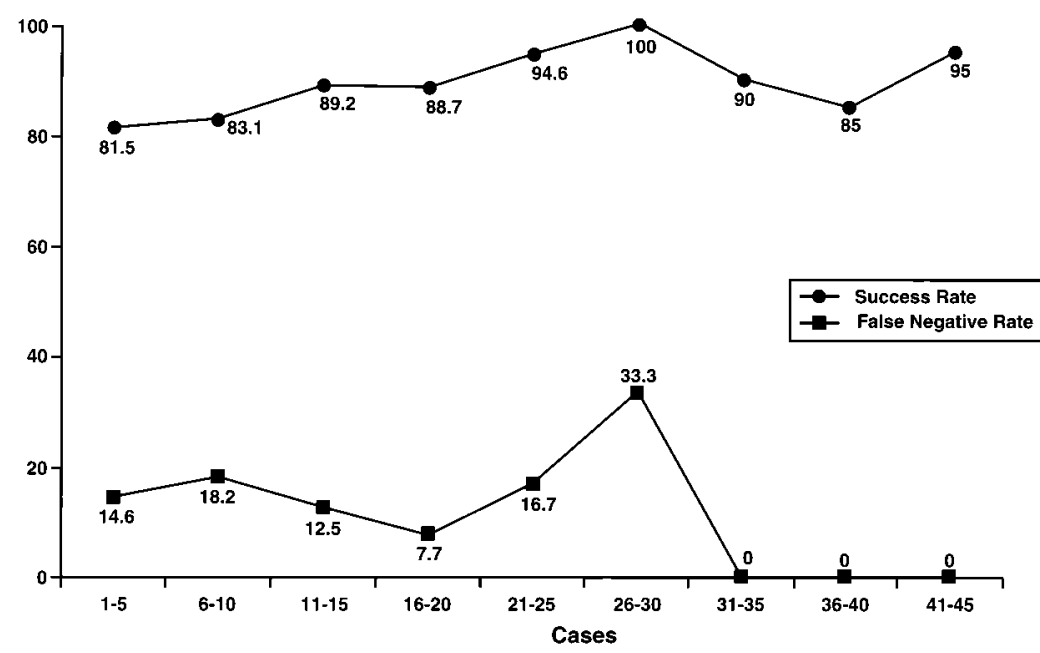

Figure 2. Positive affects (decreased false-negative rate and increased success rate of sentinel node biopsy) of increasing experience of the surgeon. 
Table 6. NUMBER OF SENTINEL NODES OBTAINED VERSUS RATE OF POSITIVITY

\begin{tabular}{lccc}
\hline $\begin{array}{c}\text { \# Sentinel } \\
\text { Nodes Found }\end{array}$ & \# Pts. & $\begin{array}{c}\text { \# Pts. With } \\
\text { Positive Sentinel } \\
\text { Nodes }\end{array}$ & $\begin{array}{c}\text { \% Sentinel } \\
\text { Node Positivity }\end{array}$ \\
\hline 1 & 190 & 39 & 20.5 \\
$\geq 2$ & 276 & 83 & 30.0 \\
$P$ value & & & .025 \\
\hline
\end{tabular}

do not support the conclusion that patients who have undergone prior breast surgery or have a larger tumor are ineligible for the procedure. These results, therefore, broaden the applicability of the technique to patients who have until now been excluded in most series.

It remains unclear whether the technique of using both IB and Tc99 is superior to using either agent alone. The single published multicenter trial using Tc99 alone ${ }^{5}$ included only experienced surgeons and achieved a false-negative rate that differed by $2 \%$ (11\% vs. $13 \%$ ) from this trial with relatively inexperienced surgeons. The combination technique may make it easier to find a sentinel node and reduce dissection time, but proof of this would require further study. The results of IB alone in experienced hands have been good. ${ }^{3,10}$ The concern with use of this agent alone, however, is that a second sentinel node may be missed, whereas a second radioactive sentinel node could be detected with the gamma probe. In addition, the finding of a "cold axilla" provides reassurance to the surgeon that all sentinel nodes have been removed. The data from this trial suggest that surgeons should not stop after finding just one sentinel node but should search thoroughly to be certain there are not more.
Table 9. TIMING OF Tc99 AND EX VIVO SENTINEL NODE COUNTS USING

FILTERED AND UNFILTERED PREPARATIONS

\begin{tabular}{ccc}
\hline $\begin{array}{c}\text { Timing of Tc99 } \\
\text { (min) }\end{array}$ & $\begin{array}{c}\text { Mean Hottest Node } \\
\text { Counts }\end{array}$ & $\begin{array}{c}\text { Mean Counts } \\
\text { All Sentinel } \\
\text { Nodes }\end{array}$ \\
\hline Filtered & & \\
$<20$ & 2,938 & 2,609 \\
$21-60$ & 24,558 & 11,563 \\
$61-240$ & 4,629 & 3,583 \\
$>240$ & 1,863 & 1,519 \\
Unfiltered & & \\
$<20$ & 2,683 & 1,816 \\
$21-60$ & 3,332 & 1,937 \\
$61-240$ & 9,178 & 5,142 \\
$>240$ & 8,683 & 5,886 \\
\hline
\end{tabular}

This is especially appropriate because first, the mean number of sentinel nodes obtained in this trial was two, and second, the false-negative rate in patients yielding one sentinel node was $20.8 \%$ compared with $9.2 \%(P=.07)$ when a second SN was sought and found.

In this large clinical trial with a relatively high falsenegative rate, we found that location of tumors in the medial quadrant increased the false-negative rate. This finding is baffling and with no obvious physiologic or anatomical explanation; it may represent a statistical error in the small population of patients with false-negative results. High false-negative rates were found in patients in whom only one sentinel node was found and with inexperienced surgeons, but these did not reach statistical significance. The number of sentinel nodes found (see Table 8), after being

Table 7. FACTORS AFFECTING NUMBER OF SENTINEL NODES FOUND

\begin{tabular}{|c|c|c|c|}
\hline Characteristic & Variable & $\begin{array}{c}\text { Mean \# of } \\
\text { Sentinel Nodes } \\
\text { Found }\end{array}$ & $\begin{array}{c}P \\
\text { Value }\end{array}$ \\
\hline \multirow[t]{3}{*}{ Tumor location } & Outer & 2.08 & \\
\hline & Inner & 1.71 & .09 \\
\hline & Central & 2.32 & \\
\hline \multirow[t]{3}{*}{ Prior surgical procedure } & Tumor intact (fine-needle aspiration or core) & 1.96 & \\
\hline & Open biopsy & 2.08 & .34 \\
\hline & Lumpectomy & 1.59 & \\
\hline \multirow[t]{2}{*}{ Tc99 preparation } & Filtered & 1.96 & \\
\hline & Unfiltered & 2.00 & .79 \\
\hline \multirow[t]{3}{*}{ Gamma probe used } & C-trak & 1.93 & \\
\hline & Neoprobe & 2.00 & \\
\hline & Navigator & 2.18 & .59 \\
\hline \multirow[t]{2}{*}{ Age at diagnosis (years) } & $<50$ & 2.51 & \\
\hline & $\geq 50$ & 1.74 & .001 \\
\hline \multirow[t]{4}{*}{ Injection interval (min) } & $<20$ & 1.57 & \\
\hline & $21-60$ & 1.61 & \\
\hline & $61-240$ & 2.21 & .01 \\
\hline & $>240$ & 1.89 & \\
\hline
\end{tabular}




\section{Table 8. EXPERIENCE VERSUS NUMBER OF SENTINEL NODES}

\begin{tabular}{lccc}
\hline Experience & $\begin{array}{c}\text { One Sentinel } \\
\text { Node }\end{array}$ & $\begin{array}{c}\text { Two Sentinel } \\
\text { Nodes }\end{array}$ & $\begin{array}{c}\text { Three Sentinel } \\
\text { Nodes }\end{array}$ \\
\hline$<30$ cases & $23(9 / 39)$ & $18(7 / 39)$ & $3(1 / 32)$ \\
$\geq 30$ cases & $11.1(1 / 9)$ & $0(0 / 6)$ & $0(0 / 10)$ \\
$P$ value & .39 & .26 & .57
\end{tabular}

Data given represent the false-negative rate, with number of cases in parentheses.

adjusted for inexperience, was significant $(P=.005$; likelihood ratio test). Although with only 18 false-negative results, the power of these results is limited, they are interesting from the standpoint that the large adjusted odds ratio for inexperience suggested that the inexperience effect is not solely due to inexperienced surgeons finding fewer sentinel nodes. Because the actual number of patients with a false-negative result is small, an even larger series of patients will be required to determine definitively which factors can predict a false-negative result.

Various injection techniques have been described, ${ }^{2,11-13}$ and it is not clear whether one is optimal. These techniques include peritumoral injection, subdermal injection, and injection of Sappey's plexus. As the area of the peritumoral injection increases (i.e., compare the injection area of a small biopsy to a lumpectomy), the number of sentinel nodes obtained might increase. If the injection technique leads to finding a large number of sentinel nodes, this ultimately dilutes the sentinel node concept. Some studies have found a lower success rate in patients who have undergone a prior breast biopsy, ${ }^{5,14,15}$ and others have not. ${ }^{3,16}$ We found that removing breast tissue for either a breast biopsy or a therapeutic lumpectomy did not statistically alter either the false-negative rate or the identification rate. These results support the hypothesis that perhaps the entire breast drains to only one or two sentinel nodes. This is further supported by not finding a greater number of sentinel nodes in patients who had a prior biopsy or lumpectomy (see Table 7). If confirmed in larger series, these data would suggest that precise injection of IB or Tc99 at the tumor site might not be necessary.

In this study, the affect of increasing patient age was significant. Not only were fewer sentinel nodes found, but they were also found less frequently. Krag et $\mathrm{al}^{5}$ reported a similar finding and hypothesized that this was secondary to the progressive replacement of the parenchyma of the lymph nodes in older patients by fat. It is also possible that with increasing age, the breast becomes progressively replaced by fat and the lymphatic vessel density decreases. Lymphatic uptake of the dye and Tc99 may become more sluggish, resulting in less concentration of the Tc99 or IB in the sentinel node, making sentinel node identification more difficult. Further research will be needed to formulate better techniques to guarantee a high success rate in the elderly population.

It has been hypothesized that as the tumor volume in the axilla increases, the success rate of SNB decreases and the false-negative rate increases. The biologic rationale behind this hypothesis is that lymphatics become progressively infiltrated with tumor cells and do not allow the passage of dyes or radionucleotides. Our identification rate was lower when patients had five or more involved axillary nodes, but this did not reach statistical significance. The small number of patients with more than five positive axillary nodes could account for this. The success rate was also lower in patients with tumor lymphovascular invasion (80\% vs. $87 \%)$. Until larger series confirm extent of axillary involvement as an important factor, it is probably wise in patients undergoing SNB alone, especially those in whom a clinical examination is difficult (i.e., obese patients), to perform intraaxillary palpation through the SNB incision. Any suspicious lymph nodes should be biopsied. The possibility of obtaining a false-negative result in a patient with bulky disease in the axilla is worrisome because that patient would be at high risk of systemic failure and might be denied chemotherapy based on the false results of the sentinel node. The patient would also be denied any possible therapeutic benefit of removing malignant lymph nodes.

We previously showed in an animal model of lymphatic mapping that use of filtered versus unfiltered Tc99 resulted in finding more sentinel nodes. ${ }^{7}$ This was not the case in this trial. Confounding factors making this comparison difficult are the different injection techniques used (peritumoral vs. subdermal) and a probable inherent difference between the swine and human lymphatic systems. We did find, however, less variation in gamma probe counts when the unfiltered preparation was used. Because neither preparation affected the false-negative rate or success rate, it is unlikely to be an important factor in the technique of lymphatic mapping with experienced surgeons. It may, however, be an important factor in decreasing the learning curve of sentinel node identification. The hotter the sentinel node, the easier it is to detect at the skin level. To obtain this using filtered takes a short injection time interval (30-60 minutes), whereas a longer injection interval may be more optimal for use of unfiltered Tc99 (60-240 minutes).

Medial quadrant tumors have posed several concerns and questions with the introduction of lymphatic mapping forbreast cancer. In some patients, a medial quadrant lesion drains to the internal mammary nodes, producing metastases in this lymphatic chain. ${ }^{17-19}$ Data from early randomized trials showed that removal of these lymph nodes could increase survival (at the cost of many complications). ${ }^{20}$ SNB has the potential to identify the group of patients at risk for these metastases by identifying an internal mammary sentinel node. Dissection of internal mammary sentinel nodes was extensively studied in one series using 10 $\mathrm{mCi}$ radiocolloid with excellent results. ${ }^{16}$ Seventy patients were described, and $34 \%$ of patients undergoing lympho- 
scintigraphy were found to have an internal mammary sentinel node $(\mathrm{n}=24)$. These were successfully dissected in $62 \%(15 / 24)$ of the patients and were found to be positive in $33 \%(5 / 15)$. Two patients had a pneumothorax. In our trial, a much lower percentage of patients (16\%) were found to have a hot spot at the internal mammary basin with counts 10 times the background count, but dissection was not performed. The difference in the rate could be attributed to the lower dose of Tc99 used in this clinical trial. It is difficult to determine whether these hot spots represent true internal mammary sentinel nodes or "shine-through" from a hot primary close to this chain of lymph nodes. The incidence of internal mammary metastases is low, and therefore a clinical trial to evaluate the therapeutic benefit of either positive internal mammary sentinel node removal or treatment of positive internal mammary nodes with radiation would be difficult. For the first time, however, it is possible, with minimal complications, to tailor treatment for patients at risk for metastases in this chain of lymph nodes.

In summary, the combined use of IB and Tc99 can identify sentinel nodes accurately but requires surgical expertise to reach what has been viewed as an acceptable level of success and an acceptable false-negative rate $(>85 \%$ and $<5 \%$, respectively). ${ }^{21}$ These data suggest that caution is required in older patients and in patients with medial quadrant lesions. Our results, however, also demonstrate the usefulness of SNB even in patients with larger tumors and those who have undergone prior breast surgery. Other factors beyond the surgeon's control, such as a large axillary tumor burden, may contribute to SNB failure. Progression to performing SNB alone by the surgical community will need to be accompanied by a thorough intraaxillary examination to attempt to decrease the false-negative rate. Although it is not well established what false-negative rate, if any, will translate into decreased survival, the technique will spare more than half of patients an axillary node dissection, which carries significant complications and provides no benefit when the lymph nodes are negative.

\section{Acknowledgments}

The authors thank all surgeons who participated in the East Carolina University Breast Sentinel Node Project. Their commitment, enthusiasm, and patience in learning this new surgical technique cannot be fully expressed. The authors thank Drs. J.W. Byrnett, Mario Cerame, and Larry Crawford from Alamance Regional Medical Center, Burlington, NC; Drs. Richard White, Peter Turk, Rhonda Wachsmuth, Charles Collin, Sharon Murray, Teresa Flippo, and Dr. Andrew Bohn and Philip Visser from Carolinas Medical Center, Charlotte, NC; Dr. Andrew Bailey from Martha Jefferson Hospital, Charlottesville, VA; Drs. David Lewis, James S. McGinn, Thomas K. Berry, and Scott O'Neil from Commonwealth Surgical Associates and Dr. Nelson Fox from Martinsville, VA; Dr. Michael Rowland from Pinehurst Surgical Clinic, Pinehurst, NC; Dr. David
Pearsall from ECU School of Medicine and Dr. John Hale from Pitt Surgical, both in Greenville, NC; Dr. Paul Hogg from Carteret Surgical, Morehead City, NC; Dr. W.K. Ruffin from Norfolk Surgical Group, Norfolk, VA; Drs. James Dumont, Paul Ulich, and Thomas Marfing from Winchester Medical Center, Winchester, VA; Drs. Peter Young, Matthew Martin, Christian Streck, David Newman, Haywood Ingram, and Anita Lindsay from Moses Cone Health Systems, Greensboro, NC; and Drs. Catherine Tucker, Amy Dubois, Kelley Cornell, Ronald Nath, and Julianne Stoughton from Winchester Hospital Breast Care Center, Woburn, MA. The principal investigator also wishes to thank Dr. Donald Morton, Dr. Armando Giuliano, and the John Wayne Cancer Institute for their support and direction.

\section{References}

1. Albertini JJ, Lyman GH, Cox C, et al. Lymphatic mapping and sentinel node biopsy in the patient with breast cancer. JAMA 1996; 276:18181822.

2. Giuliano AE, Kirgan DM, Guenther JM, Morton DL. Lymphatic mapping and sentinel lymphadenectomy for breast cancer. Ann Surg 1994; 220: 391-398.

3. Guenther JM, Krishnamoorthy M, Tan LR. Sentinel lymphadenectomy for breast cancer in a community managed care setting. Cancer J Sci Am 1997; 3:336-340.

4. Hill ADK, Tran KN, Akhurst T, et al. Lessons learned from 500 cases of lymphatic mapping for breast cancer. Ann Surg 1999; 229:528-535.

5. Krag D, Weaver D, Ashikaga T, et al. The sentinel node in breast cancer-a multicenter validation study. N Engl J Med 1998; 339:941946.

6. Cox C, Pendas S, Cox J, et al. Guidelines for sentinel node biopsy and lymphatic mapping of patients with breast cancer. Ann Surg 1998; 227:645-653.

7. Tafra L, Chua A, Lannin D, et al. Filtered vs. unfiltered technetium sulfur colloid (Tc99) in lymphatic mapping in a pig model. Ann Surg Oncol 1999; 6:83-87.

8. Krag DN, Weaver DL, Alex JC, Fairbank JT. Surgical resection and radiolocalization of the sentinel lymph node in breast cancer using a gamma probe. Surg Oncol 1993; 2:335-339.

9. Gillian AE, Dale PS, Turner RR, et al. Improved axillary staging of breast cancer with sentinel lymphadenectomy. Ann Surg 1995; 222:394-401.

10. Giuliano AE, Jones RC, Brennan M, Statman R. Sentinel lymphadenectomy in breast cancer. J Clin Oncol 1997; 15:2345-2350.

11. Beitsch $\mathrm{P}, \mathrm{Clifford} \mathrm{E}$. Improved lymphatic mapping technique for breast cancer. Society of Surgical Oncology, 52nd Cancer Symposium; 1999:35.

12. Veronesi U, Paganelli G, Galimberti V, et al. Sentinel-node biopsy to avoid axillary dissection in breast cancer with clinically negative lymph nodes. Lancet 1997; 349:1864-1867.

13. Linehan DC, Akhurst T, Hill ADK, et al. Intradermal radiocolloid and intraparenchymal blue dye injection optimizes sentinel node identification in breast cancer patients. Ann Surg Onc 1999; 6:450-454

14. Albertini J, Lyman G, Cox C, et al. Lymphatic mapping and sentinel node biopsy in the patient with breast cancer. JAMA 1996; 276:1818.

15. Borgstein PJ, Meijer S, Pijpers R. Intradermal blue dye to identify sentinel lymph node in breast cancer. Lancet 1997; 349:1668-1669.

16. Van der Ent FWC, Kengen RAM, Van der Pol HAG, Hoofwijk AGM. Sentinel node biopsy in 70 unselected patients with breast cancer: increased feasibility by using $10 \mathrm{mCi}$ radiocolloid in combination with a blue dye tracer. Eur J Surg Oncol 1999; 25:24-29.

17. Veronesi U, Cascinelli N, Bufalino R, et al. Risk of internal mammary lymph node metastases and its relevance on prognosis of breast cancer patients. Ann Surg 1983; 12:681-684. 
18. Le M, Arriagada R, de Vathaire F, et al. Can internal mammary chain treatment decrease the risk of death for patients with medial breast cancers and positive axillary lymph nodes? Cancer 1990; 66:2313-2318.

19. Noguchi M, Michigishi T, Nakajima K, et al. The diagnosis of internal mammary node metastases of breast cancer. Int Surg 1993; 78:171175.
20. Lacour J, Bucalossi P, Cacers E, et al. Radical mastectomy versus radical mastectomy plus internal mammary dissection. Cancer 1976; 37:206-214.

21. Edwards M, Giuliano A, Reintgen D, Tafra L. Consensus statement on guidelines for performance of sentinel lymph node biopsy for breast cancer. American Society of Breast Surgeons Quarterly 1998;fall: 3. 